Jurnal Pemberdayaan: Publikasi Hasil Pengabdian kepada Masyarakat

Vol. 2, No. 1, April 2018, Hal. 43-50

ISSN: 2088 4559; e-ISSN: XXXX-XXXX

DOI:

\title{
PEMBERDAYAAN MASYARAKAT MELALUI PROGRAM PERILAKU HIDUP BERSIH DAN SEHAT DI KAMPUNG KAUMAN KOTA YOGYAKARTA
}

\author{
Rostien Puput Anggoro ${ }^{1}$, Luthfia Isna Rachmi ${ }^{2}$, Enggar Tri Aulia $^{3}$ \\ Universitas Ahmad Dahlan, Yogyakarta ${ }^{1,2,3}$ \\ rostien.anggoro@pmat.uad.ac.id ${ }^{1}$
}

\begin{abstract}
ABSTRAK
Salah satu tema KKN Alternatif di Kampung Kauman, Kecamatan Gondomanan, Kota Yogyakarta adalah Program Kesehatan Lingkungan dalam masyarakat. Hal ini terlihat masih terdapat masyarakat yang belum sadar akan pentingnya menjaga kebersihan di lingkungan sekitar rumah warga. Maka Kuliah Kerja Nyata Alternatif LXI Divisi I.D menggelar program kesehatan lingkungan bagi warga Kampung Kauman. Metode pelaksanaan program KKN meliputi pendidikan masyarakat dan praktek. Bentuk kegiatannya yaitu penyuluhan PHBS (Perilaku Hidup Bersih dan Sehat) dan penyuluhan kesehatan masyarakat serta olahraga senam rutin. Program ini bertujuan untuk memberdayakan masyarakat Kampung Kauman dalam program kesehatan masyarakat dan lingkungan. Dampak dari kegiatan ini adalah: 1) masyarakat dapat meningkatkan pengetahuan pentingnya tentang perilaku hidup bersih dan sehat, 2) masyarakat dapat menciptakan kesadaran untuk dapat menjaga dan menerapkan perilaku hidup bersih dan sehat, 3) ibu-ibu lansia dapat meningkatkan pengetahuan tentang cara menjaga alat reproduksi wanita.
\end{abstract}

Kata kunci: pemberdayaan, kampung Kauman, kesehatan .

\begin{abstract}
One of the themes of Alternative KKN in Kauman Village, Gondomanan District, Yogyakarta City is the Environmental Health Program in the community. This can be seen that there are still people who are not aware of the importance of maintaining cleanliness in the surrounding neighborhoods. Then the LXI Division I.D Real Alternative Work Lecture held an environmental health program for the residents of Kauman Village. Methods of implementing the Community Service Program include community education and practice. The forms of activities are PHBS (Clean and Healthy Behavior) counseling and public health counseling and routine gymnastics. The program aims to empower the Kauman Village community in community and environmental health programs. The impacts of this activity are: 1) the community can increase its important knowledge about clean and healthy behavior, 2) the community can create awareness to be able to maintain and implement clean and healthy lifestyle, 3) elderly mothers can increase their knowledge on how to maintain their reproduction .
\end{abstract}

Keywords: empowerment, Kauman village, health. 


\section{PENDAHULUAN}

Kampung Kauman merupakan salah satu kampung dari yang terletak di Kelurahan Ngupasan, Kecamatan Gondomanan, Kota Yogyakarta, Provinsi Daerah Istimewa Yogyakarta. Adapun data yang didapatkan berupa data kependudukan seperti: batas wilayah, luas wilayah penggunaan, iklim, jenis dan kesuburan tanah pembagian administratif, kondisi keagamaan, kondisi perekonomian, kondisi pendidikan, serta struktur dan program kerja dari setiap struktur keorganisasian yang ada di kampung Kauman. Kelurahan Ngupasan memiliki luas wilayah 66,86 Ha dengan batas wilayah sebelah utara yaitu Kelurahan Sosromenduran, Kecamatan Gedongtengen, batas wilayah sebelah selatan yaitu Kelurahan Prawirodirjan dan Kelurahan Kadipaten, batas wilayah sebelah timur yaitu Kelurahan Purwokinanti Kecamatan Pakualaman, dan batas wilayah sebelah barat yaitu Kelurahan Notoprajan dan Kelurahan Ngampilan.

Menurut Munawar (2011), Pemberdayaan masyarakat adalah konsep pembanguan ekonomi yang merangkum nilai-nilai masyarakat untuk membangun paradigma baru dalam pembangunan. Sedangkan Harahap (2012), menambahkan definisi pemberdayaan masyarakat adalah suatu usaha untuk memulihkan atau meningkatkan keberdayaan suatu komunitas agar mampu berbuat sesuai dengan harkat dan martabat mereka dalam melaksanakan hak-hak dan tanggung jawab mereka sebagai komunitas manusia dan warga negara. Tujuan pemberdayaan masyarakat adalah untuk mencapai sebuah perubahan sosial, yaitu masyarakat yang berdaya, memiliki pengetahuan dan kemampuan dalam memenuhi kebutuhan hidupnya baik yang bersifat fisik, ekonomi maupun sosial, dan juga diharapkan akan terwujud kehidupan masyarakat yang lebih baik.

Ada beberapa bentuk pemberdayaan masyarakat, salah satunya adalah pemberdayaan masyarakat dalam bidang kesehatan. Winslow dalam Notoatmodjo (2003) kesehatan masyarakat (Public Health) adalah Ilmu dan Seni: mencegah penyakit, memperpanjang hidup, dan meningkatkan kesehatan, melalui "usaha-usaha pengorganisasian masyarakat". Menurut WHO tujuan kesehatan masyarakat baik dalam bidang promotif, preventif, kuratif dan rehabilitatif adalah tiap warga masyarakat dapat mencapai derajat kesehatan yang setingitingginya baik fisik, mental, sosial serta diharapkan berumur panjang.

Dengan adanya pemberdayaan masyarakat diharapkan masyarakat dapat lebih memperhatikan kesehatan. Program pemberdayaan masyarakat diupayakan untuk meningkatkan kesehatan masyarakat RW 12 Kampung Kauman. Masyarakat diharapkan lebih peduli untuk menjaga kebersihan lingkungan untuk menjaga kesehatan diri sendiri dan 
keluarganya. Kegiatan yang dilakukan dalam rangka meningkatkan kesehatan masyarakat adalah penyuluhan PHBS (Perilaku Hidup Bersih dan Sehat) dan penyuluhan kesehatan wanita serta Senam Rutin warga. Program ini bertujuan untuk memberdayakan masyarakat Kampung Kauman dalam program kesehatan masyarakat dan lingkungan.

\section{METODE}

Untuk meningkatkan kualitas kesehatan masyarakat yang ada di Kampung Kauman, metode yang diterapkan adalah melalui pendidikan masayarakat dengan menyelenggarakan penyuluhan PHBS (Perilaku Hidup Bersih dan Sehat) dan Penyuluhan Kesehatan Wanita, serta praktek langsung dengan menyelenggarakan Senam Rutin. Rincian metode pelaksanaan, bentuk kegiatan, JKEM, dan jumlah mahasiswa yang terlibat tersaji dalam Tabel 1.

Tabel 1. Metode, Kegiatan, JKEM, dan Jumlah Mahasaiswa Terlibat

\begin{tabular}{|c|c|c|c|c|}
\hline No & Metode & Kegiatan & JKEM & $\begin{array}{c}\text { Jumlah } \\
\text { mahasiswa } \\
\text { yang terlibat }\end{array}$ \\
\hline 1 & $\begin{array}{l}\text { Pendidikan } \\
\text { Masyarakat } \\
\text { (Penyuluhan } \\
\text { PHBS) }\end{array}$ & $\begin{array}{l}\text { Memberikan penjelasan tentang } \\
\text { PHBS (Perilaku Hidup Bersih dan } \\
\text { Sehat) bagi masyarakat RW } 12 \\
\text { Kauman } \\
\text { Menayangkan video tentang } \\
\text { penerapan PHBS (Perilaku Hidup } \\
\text { Bersih dan Sehat) bagi masyarakat } \\
\text { RW } 12 \text { Kauman }\end{array}$ & $1 \times 120^{\prime}$ & 9 orang \\
\hline 2 & $\begin{array}{l}\text { Pendidikan } \\
\text { Masyarakat } \\
\text { (Penyuluhan } \\
\text { Kesehatan Wanita) }\end{array}$ & $\begin{array}{l}\text { Memberikan penjelasan tentang } \\
\text { organ wanita bagi lansia Kauman } \\
\text { Memberikan tips menjaga kesehatan } \\
\text { reproduksi wanita bagi lansia } \\
\text { Kauman } \\
\text { Memberikan penjelasan tentang } \\
\text { penyakit yang dapat menyerang } \\
\text { organ reproduksi wanita bagi lansia } \\
\text { Kauman }\end{array}$ & $1 \times 120^{\prime}$ & 9 orang \\
\hline
\end{tabular}




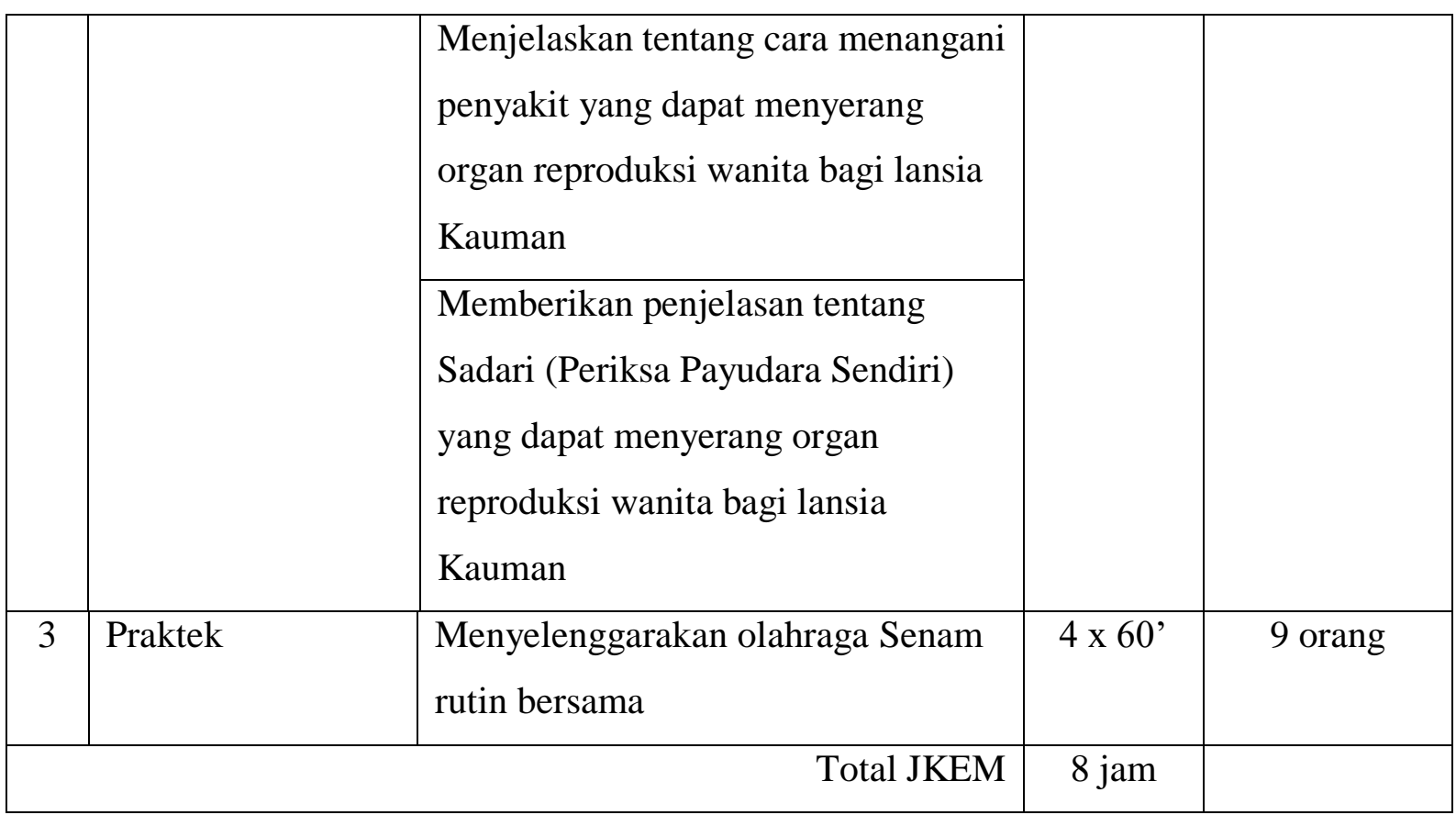

\section{HASIL, PEMBAHASAN, DAN DAMPAK}

Masing-masing kegiatan dilaksanakan pada waktu yang berbeda. Mulai dari yang pertama adalah penyuluhan PHBS (Perilaku Hidup Bersih dan Sehat) bagi warga RW 12 Kauman, dan selanjutnya penyuluhan kesehatan wanita penyuluhan, serta kegiatan Senam rutin bersama. Rincian dari kegiatan tersebut dapat dijelaskan sebagai berikut:

\section{Penyuluhan PHBS (Perilaku Hidup Bersih dan Sehat)}

Perilaku hidup bersih dan sehat (PHBS) pada hakekatnya merupakan perilaku pencegahan oleh individu atau keluarga dari berbagai penyakit. Salah satu sasaran penerapan program PHBS adalah pada tatanan rumah tangga, yang bertujuan untuk meningkatkan derajat kesehatan keluarga dan produktivitas kerja setiap anggota keluarga (Depkes RI, 2006). Tujuan khusus dari PHBS adalah meningkatkan pengetahuan, sikap dan perilaku masyarakat khususnya dan rumah tangga terhadap program KIA (Kesehatan Ibu dan Anak), gizi, kesehatan lingkungan, gaya hidup, dan JPKM (Jaring Pengaman Kesehatan Masyarakat). Kegiatan PHBS memiliki sasaran primer, sasaran sekunder, dan sasaran tertier, dengan sasaran utama adalah mengubah perilaku individu anggota keluarga yang bermasalah (Rochimah, 2009).

PHBS adalah upaya untuk memberikan pengalaman belajar atau menciptakan suatu kondisi bagi perorangan, keluarga, kelompok dan masyarakat, dengan membuka jalur komunikasi, memberikan informasi dan edukasi untuk meningkatkan pengetahuan, sikap dan 
perilaku, sehingga membantu masyarakat mengenali dan mengatasi masalah sendiri, dalam tatanan rumah tangga, agar dapat menerapkan cara-cara hidup sehat dalam rangka menjaga, memelihara, dan meningkatkan kesehatan. PHBS dilaksanakan pada tanggal 3 Desember 2018. Persiapan untuk melaksanakan kegiatan ini dimulai 1-2 Desember 2018. Persiapan yang dilakukan seperti koordinasi dengan pihak RW 12 Kauman, menyiapkan materi serta membuat leaflet tentang PHBS.

Penyuluhan PHBS diselenggarakan di Gedung Aisyiyah Kauman. Penyuluhan ini diikuti oleh warga RW 12 Kauman yang berjumlah 100 orang. Hal yang pertama dilakukan adalah pemateri memberikan penjelasan tentang PHBS dan selanjutnya menayangkan video tentang penerapan PHBS. Di akhir acara Ketua RW 12 Kauman mengumumkan kejuaraan Lomba Hatinya PKK, Cerdas Cermat PKK, Lomba Proklim, Lomba Tonis, Lomba Gebyar TPA dan Penghargaan setiap RT atas partisipasi dalam kegiatan RW 12.

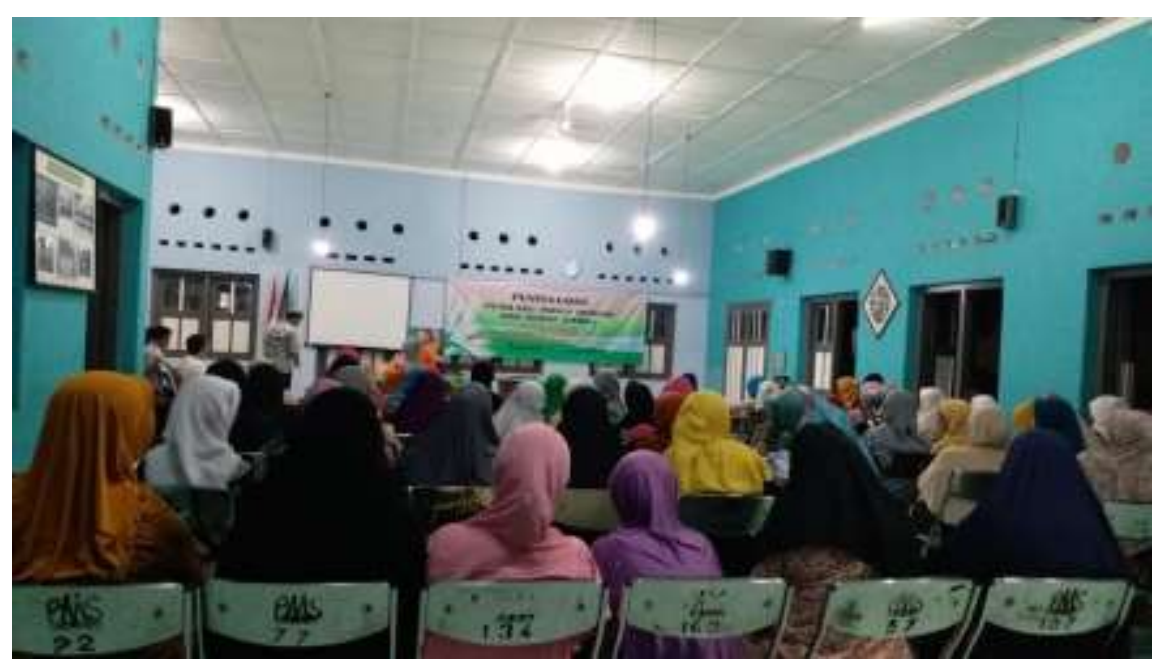

Gambar 1. Penyuluhan PHBS

\section{Penyuluhan Kesehatan Wanita}

Kesehatan merupakan salah satu hal penting yang mempengaruhi kualitas kehidupan seseorang. Menjaga kesehatan membutuhkan usaha dan pengetahuan agar mendapatkan hasil yang optimal. Ada beberapa pengetahuan tentang kesehatan yang khusus seperti pengetahuan tentang kesehatan reproduksi wanita yang akan berkaitan langsung dengan pengetahuan tentang sistem reproduksi wanita, resiko-resiko yang ada hingga pengetahuan tentang cara menjaga kesehatan organ khusus tersebut. Dengan bekal pengetahuan yang cukup maka para wanita dapat menjaga kesehatan dirinya agar terhindar dari berbagai masalah kesehatan reproduksi. 
Penyuluhan kesehatan wanita dilaksanakan pada tanggal 5 Desember 2018. Persiapan untuk melaksanakan kegiatan ini dimulai 4 Desember 2018. Persiapan yang dilakukan seperti koordinasi dengan pihak lansia Kauman dan menyiapkan materi tentang kesehatan wanita. Penyuluhan Kesehatan diselenggarakan di Gedung Al Falah. Penyuluhan ini diikuti oleh lansia Kauman yang berjumlah 50 orang. Hal yang pertama dilakukan adalah memberikan penjelasan tentang organ wanita bagi lansia Kauman. Selanjutnya, memberikan tips menjaga kesehatan reproduksi wanita bagi lansia Kauman. Kemudian memberikan penjelasan tentang penyakit yang dapat menyerang organ reproduksi wanita bagi lansia Kauman. Menjelaskan tentang cara menangani penyakit yang dapat menyerang organ reproduksi wanita serta memberikan penjelasan tentang Sadari (Periksa Payudara Sendiri).

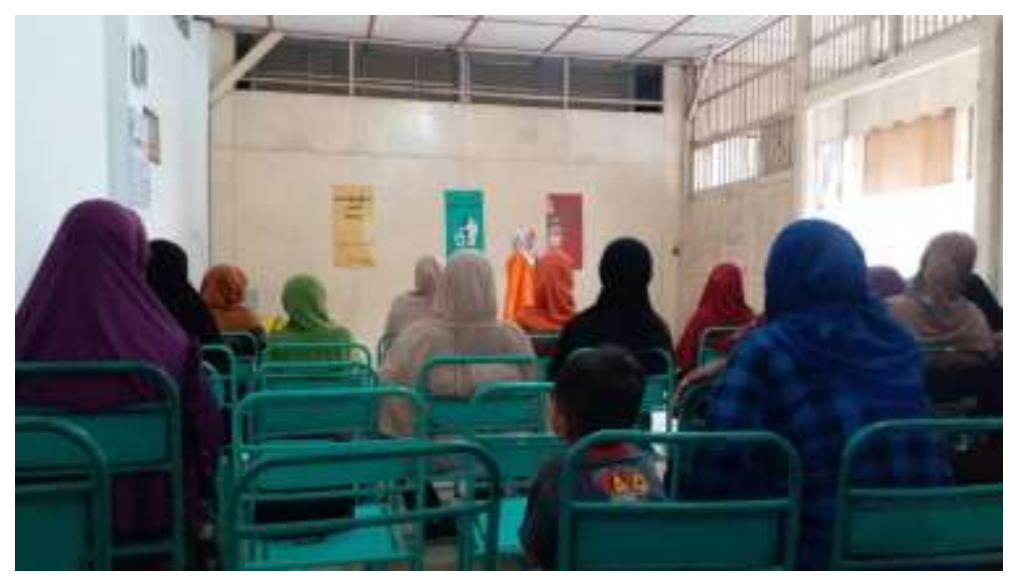

Gambar 2. Penyuluhan Kesehatan Wanita

\section{Senam Rutin Bersama}

Kegiatan senam rutin dilaksanakan setiap hari Ahad pada pukul 06.00 sampai dengan 07.00 bertempat di halaman Masjid Besar Kauman. Kegiatan senam ini diikuti oleh seluruh warga Kauman dari segala jenjang, dari anak-anak, remaja, dan dewasa maupun lansia.

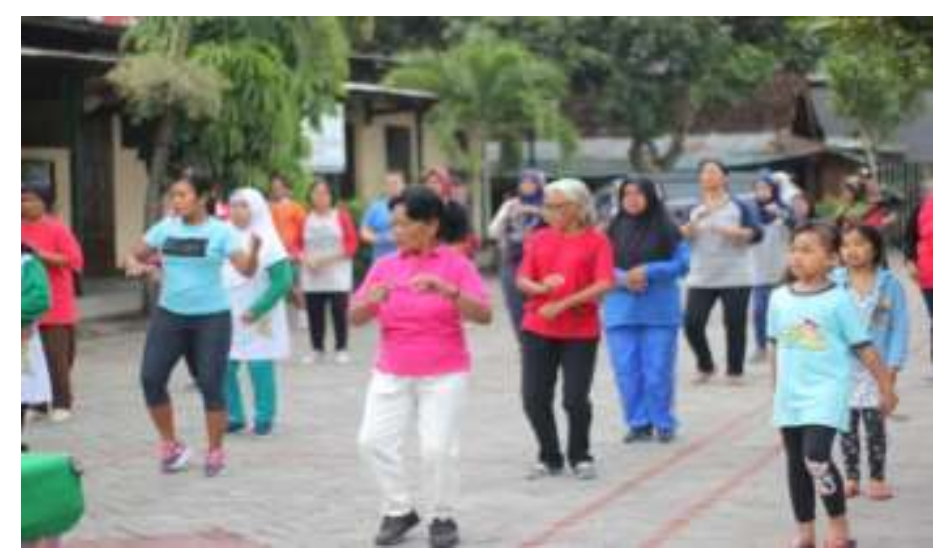

Gambar 3. Senam Rutin Bersama 
Dari seluruh kegiatan penyuluhan dan senam rutin di atas, dampak yang akan didapatkan adalah:

a. Bagi masyarakat dapat meningkatkan pengetahuan pentingnya tentang perilaku hidup bersih dan sehat.

b. Bagi masyarakat dapat menciptakan kesadaran untuk dapat menjaga dan menerapkan perilaku hidup bersih dan sehat.

c. Bagi ibu-ibu lansia dapat meningkatkan pengetahuan tentang cara menjaga kesehatan alat reproduksi wanita.

\section{SIMPULAN}

Dari apa yang telah dijabarkan di atas, kesimpulan yang didapatkan antara lain:

1. Dengan metode penyuluhan yang diterapkan dengan teori dan contoh diharapkan dapat menambah pengetahuan bagi warga Kampung Kauman tentang pentingnya perilaku hidup bersih dan sehat.

2. Dari kegiatan-kegiatan tersebut dampak yang didapatkan yakni masyarakat RW 12 Kauman dapat menjaga dan menerapkan perilaku hidup bersih dan sehat serta menjaga kesehatan alat reproduksi wanita.

3. Dari hasil menjaga dan menerapkan perilaku hidup bersih dan sehat serta menjaga kesehatan alat reproduksi wanita sehingga terwujud masyarakat yang sehat.

\section{DAFTAR PUSTAKA}

Departemen Kesehatan RI. (2006). Promosi Kesehatan: Buku Saku Bidan Poskesdes. Jakarta. Departemen Kesehatan RI.

Harahap E.F.. 2012. Pemberdayaan masyarakat dalam bidang ekonomi untuk mewujudkan ekonomi nasional yang tanggung dan mandiri. Jurnal Manajemen dan Kewirausahaan. Vol.3 (2). Hal. 78-96.

Munawar N., 2011. Pemberdayaan masyarakat. Jurnal Ilmiah CIVIS, Volume I, No 2, Hal. $87-99$

Notoatmodjo, S., 2003. Pengembangan sumber daya manusia. Jakarta. PT. Rineka Cipta. 
Rachimah. T.H.N. 2009. Evaluasi pelaksanaan kampanye sosial perilaku hidup bersih dan sehat untuk menurunkan angka diare di Kabupaten Kulonprogo. Jurnal Ilmu Komunikasi, Volume 6, Nomor 1, Juni 2009, UAJY, Yogyakarta. Hal : 65-85. 